\title{
COVID-19 Pandemic and University Teachers' Experiences about Challenges of Online Teaching: A Phenomenography Approach
}

\author{
Sufiana Khatoon \\ Professor of Education \\ Former Director Publication / Former Dean Faculty of Social Sciences National University of \\ Modern Languages (NUML) Islamabad, Pakistan. \\ sufianak1@gmail.com \\ Nasreen Akhter \\ Professor of Education, \\ Chairperson Department of Special Education The Islamia University of Bahawalpur \\ drnasreenakhtar01@gmail.com \\ Nadeem Talib \\ Director Academic, National University of Modern Languages (NUML) Islamabad, Pakistan \\ ntalib@ numl.edu.pk
}

\begin{abstract}
With the advent of current Corona pandemic /COVID-19, the universities around the world were closed for face -to- face education. In the pandemic crisis, universities had to transform teaching- learning milieus instantly and online teaching went viral at universities. This transition from on campus to online education delivery services affected university teachers in many ways. By applying phenomenography approach, the present paper examines university teachers' perceptions about the challenges they faced in Pakistani context, university teachers' re-action towards university decision about the overnight teaching paradigm shift from face-to- face to online teaching, institutional support to teachers for online teaching; students' caliber for online learning, and to assemble university teachers' opinion about the pre- requisites of online teaching. The data was collected through written answers to open- ended research questions. Interpretative phenomenography analysis (IPA) framework was used to extract finding from the text data. The major findings emerged that mostly university teachers accepted the transition of teaching paradigm however some were under stressed for the online teaching. The training provided to teachers was not sufficient to meet actual requirements of online teaching. Teachers realized that universities did not have up-graded relevant infrastructure required for online education. Teachers perceived that mostly students did have the caliber to learn online moreover many students who were living in the remote areas did not have resources to get benefit from online classes. There was common consensus among university teachers that before launching online educational programs all pre- requisites of online education may be fulfilled at satisfactory level to achieve the targets.
\end{abstract}

Keywords: challenges, university teacher, phenomenography, quality online education, interpretative phenomenography analysis 


\section{Introduction}

The global Corona outbreak, an unprecedented health crisis that has severely impacted the local and international economies and societies resulting in uncertainty, fear, and helplessness. The pandemic also deeply impacted human resources and specifically the educational sector (Hamouche S, 2021; Mazumder \& et.al, 2021). As a result, educational Institutions were closed due to an increase in corona cases across the globe. This closure has affected $89.4 \%$ of enrolled students in the world (Marinoni, G., Van't Land, H., \& Jensen, T., 2020; UNESCO, 2020).

Though, serious threats, the pandemic also provided opportunities in the education sector and compelled the stakeholders to shift on synchronous and asynchronous modes of teaching for continued learning and to resume the teaching and learning practices on an immediate basis. This further forced educational leadership to invest in Technology and related infrastructure. Therefore, the current situation of COVID- 19 also compelled the stake holders of higher education to launch online teaching services for students on immediate basis. The educational institutions around the world were closed in February 2020. As a result, the universities around the world transformed teaching learning milieus instantly and online teaching went viral as the only mode at universities. According to UNESCO (2020), report almost $70 \%$ of the world's students have not been attending schools due to closure of institutions during COVID-19 pandemic. This situation is new for educators and students in the history of education that has compelled educationists to face a new regime to run the systems online. By tradition, the conventional system of education prevails in the world at large stance that has specific traditions and rules in functioning the systems. Teaching academia involved in teaching process is trained in a different way. The major parameter for bringing improvement in teaching-learning processes is to modify the routine practices of teaching and to bring changes in the ways of teaching, assessment of students' performance, re- assessing one's own teaching quality, self-realization, reflection and self-evaluation about the roles of a teacher in teaching paradigms.

Currently, it can be observed a paradigm shift from face to face to online teaching and blended / hybrid learning programs in order to use the campus facilities to support learning in a hybrid mode. Therefore, we do not have specific evidences regarding the benefits and limitations of online and face to face teaching. Resultantly, we do not have any theory which can support the logic. Before COVID-19, although online teaching was in practice all over the world, however, after the advent of COVID-19, it became compulsion for each higher education institution to present educational programs through online teaching- learning. The dimensions of higher education teaching and learning were transformed into online education. There are research evidences which highlight the challenges related to online teaching and learning. For example, Kebritchi, Lipschuetz, \& Santiague, (2017) research findings have determined the major challenges relating to online teaching and learning like students' readiness, expectations, identity and participation in online programs and the changing roles of teachers from face to face to online regarding teaching styles, teachers' competence in integration of content in multimedia, selecting teaching strategies for teaching of certain content. In order to address the challenges of online teaching, higher education institutions require to provide training as professional development for teachers to develop their competence for online teaching, content development and delivery for online scenarios and also arrange training sessions for students regarding learning in online learning environment.

Research also suggests that transition in teaching and learning environment from face to face to online, there are certain problems associated like time consumption, competence of 
teaching for online instruction delivery. However, this transition has also opened new opportunities for teachers and students and a significant one is to develop one's competence in technology usage and in online teaching and learning (Lichoro, 2015).

Preparing teachers for online teaching requires in depth need assessment / analysis of the situation. It means to have a detailed assessment of teachers' competence regarding teaching knowledge-based, technology-rich, and digital classrooms. Currently, in online teaching- learning environments, teachers' and learners' competence dimensions have been changed. The effectiveness of teaching, whether face to face or online teaching can be determined from one major parameter that students are at the center of the latest learning standards (Schweisfurth, 2015).

Keeping in view the importance of the recent research area, we decided to explore the challenges that university teachers have been facing regarding online teaching by focusing on the context of Pakistan. We believe that the findings of this research will be supportive in resolving the challenges related to quality online teaching.

\section{Literature Review}

The most prominent feature of $21^{\text {st }}$ century is the provision of online education, which may be called as borderless education and it has some salient features like its system is flexible in the context of time and space. The online education courses provide students an opportunity to study the course at their own convenient, along with fulfilling their workplace requirements and family responsibilities. It can be noticed that during last few decades, the number of students' enrollment in online courses has become greater than the enrollment in face to face higher education programs (Allen \& Seamen, 2014).

COVID-19 pandemic introduced everyone to the world of online teaching and learning. Resultantly, teachers were also introduced to online teaching programs and teaching gadgets like Zoom, Google, Meet, Google Hangouts, Skype, Adobe Connect, etc. Likewise, institutions developed their online teaching - learning policies, instructions and protocols for teachers and students for attending classes (Saxena, 2020).

Discussing the importance of online teaching and learning, Singh \& Thurman (2019) consider online teaching- learning environment more innovative in nature, student- centered, and flexible than on campus teaching- learning. Online teaching- learning is also described as a learning experience in online learning environments where different devices (e.g., mobile phones, laptops, etc.) are used through internet access. In such learning environments, students can learn independent of time and place and interact with their teachers online (Singh \& Thurman, 2019).

Talking about the quality components of online education, Basilaia et al., (2020) indicate that the components of a successful online educational program are: video conferencing, keeping classes lively, quality internet connections, lectures are accessible in multiple modes, rapid feedback from students through assignments regarding quality of the course and instruction.

We observed that after COVID-19 outbreak, there was an overnight shift of face to face conventional classrooms into electronic classrooms, along with compelling teachers to transform their entire pedagogy to tackle the new changing scenarios. The quality of online teaching and learning has become a big challenge to the world all over and there is a great concern about how academic institutions will gain and maintain quality in huge number of online teaching- learning education programs (Carey, 2020).

Currently, teachers, who are in transition period of face to face to an online environment, are aware of the integral challenges and the requirements of quality teaching- learning and 
adherence to accreditation standards but they do not receive substantial training while which is the most important aspect of online teaching, and it requires training in how to integrate content knowledge, technology, and pedagogy effectively. There are certain budget constraints but inspite of these constraints, institutions are focusing on the professional development of teachers regarding best practices for the online classrooms but teachers still have ambiguous perceptions about online education (Allen \& Seamen, 2011).

Considering the innovation implementation in teaching practices, the basic pre- requisite is to train the target group of teachers in advance for successful implementation of innovation. Therefore, quality training in how to teach online is an important pre-requisite of effective online education programs. The research shows that teachers are the basic pillars from face to face classroom teaching to online teaching and such new roles of teachers of course require training and "A significant gap exists between preferred and actual online instructional practices" (Bonk; 2001, Sammons, 2003).

Recently, González-Sanmamed et al., (2014) investigated university teachers' online proficiency in their social, evaluative, managerial, technological, counselling, personal, and research through a qualitative approach based on sample from a Spanish university. They found that university teachers emphasized the importance of quality teaching. Therefore, the professional development programs for teachers should include training on instructional practices as well as training on the teachers' roles of social, evaluative, managerial, technological, counselling, personal, and research, etc.

The major challenge in maintaining quality of online teaching is to make sure that teachers are sensible and thoughtful about the best practices of online teaching and institutions have required resources and implement guidelines for the quality teaching. Thinking about the readiness of the universities' systems to adopt prompt changes in such a small period of time, it was obvious that academic institutions would not be able to adapt all educational programs from face to face into online resource instantly. There were challenges like distance, instruments and personalized teaching and learning (Liguori\& Winkler, 2020).

QA (Quality Assurance) methods used for face-to-face teaching quality assurance, can be applied to online program for quality assurance by slightly adjusting the difference in delivery method. Considering the importance of quality assurance process of online education programs, Butcher and Hoosen (2014) have mentioned that the quality distance education is a sub-set of quality education therefore, distance education should be subjected to the same quality assurance procedures and processes in as education generally.

It is essential to have a check on the quality of online education. However, ensuring quality in online education is not rocket science. Deliberating the quality of online education/ learning assessment, Jung and Latchem (2012), suggest that to ascertain the quality in online teaching and assessment, we should target the outcomes, adopt a systemic approach for quality assurance (QA), continuous QA process of improvement and promote an internal culture of quality control.

\section{Purpose of the present research}

We have observed that a paradigm shift in teaching -learning scenarios came quickly due to the sudden arose of COVID-19 pandemic during the beginning of 2020. During this era, the whole education systems, the world over, became online. Soon after the arose of COVID-19, there have been many researches that analyzed the situation of online teaching- learning however, we detected no research that had explored university teachers' experiences regarding challenges of online teaching mode during COVID-19 in the context of Pakistan. Keeping in view this research gap, we decided to explore university teachers' perceptions regarding required teaching the 
challenges and problems that teachers have been facing during online delivery of the course in the context of resources. We further explored university teachers' perception about pre- requisites of quality online education programs. Keeping in view the current situations, the following major research questions were explored in the present the study:

(1) What is the university teachers' re-action about transition from face-to-face teaching to online teaching?

(2) What are the challenges that university teachers face during transition from face-toface classroom teaching to online teaching?

(3) What are university teachers' experiences regarding institutional support and infrastructure during transition period?

(4) What are university teachers' views about caliber and resources of students for learning through online?

(5) What are university teachers' perceptions about the pre- requisites of quality based online education programs?

\section{Method}

It was qualitative and post ex- facto research. Qualitative research procedures generally involves collecting, organizing and interpreting textual data which is derived from participants' experiences and perceptions. Through the use of qualitative research we ascertain complex social phenomena as people experienced and perceived it in order to get deeper insight into that phenomena. For the present paper phenomenography research approach was considered that best to analyze answer to the research questions of this research paper. Phenomenography is a qualitative research approach which aimed at exploring the experiences of people in conceptualizing perceiving, and understanding a phenomena in the world (Limburg, 2008). In phenomenography data are analyzed according to the perceptions that emerge from the data into specific "categories of description" and the conceptual meanings of the phenomenon of interest are identified. The identified findings are labelled under different categories of the phenomenon in the context of participants' perception (Marton \& Pong, 2005).

\section{Sample}

We collected data through certain open- ended questions which were sent to those teachers who had relevant experience of teaching in online classes during pandemic period, therefore the sample was purposive. The benefit of purposive sampling is that enables us to detect valid and defined sample for whom the research questions were relevant and significant (Dima \& Bucu, tă 2016). The sample of the present study comprised 39 university teachers. For the present research purposive sampling was used to select sample for the study and only those university teachers were requested to share their experiences who had been directly involved in online teaching - learning process during COVID-19 pandemic period. At the end of the semester, these sample teachers were given open- ended questions to share their experiences and opinion in the context of online teaching scenarios. Data were collected only from volunteer teachers who were ready to share their experience and views willingly about the current research parameters. Thirty nine teachers participated in this research. Creswell (2012, p. 76) describes that a phenomenological research expresses the common meaning for numerous individuals of their occupied and personal experiences about a concept or phenomenon. The process of phenomenological research involves to collect information through in-depth interviews with at least 10 individuals. The most important 
factor in phenomenological research is to illustrate the meaning of the phenomenon as it is experienced and perceived by a small number of individuals (Creswell 2013, p. 161).

\section{Research Instrument and Data Collection}

Valid findings can be made only if we are using suitable instrument for data collection. A questionnaire based on open ended questions was considered the best tool for collecting valid information for a qualitative research. The participants were given 10 relevant questions and requested to write their free opinions regarding their online teaching experiences. Two experts validated these questions items and then these open-ended questions were distributed to 50 teachers. However, we received replies only from 39 participants. We developed 10 open ended question items to collect data for the present study. A team of experts further validated these items. After experts' validation and field testing, we modified some items to make them self-explanatory. We collected data for the present study through online Google form and through face to face visit of the participants. We sent online Google form created questionnaire through emails and WhatsApp sharing with at least 50 participants.

\section{Procedure of data analysis}

For the analysis of open -ended question items, we used Interpretative Phenomenological Analysis (IPA) theoretical framework and adopted the procedure of IPA as suggested by Smith \& Eatough, (2006); Smith et al.; (2009) and Finlay, (2011). IPA, comparatively, is recent and modern addition in methods of qualitative research. Jonathan Smith (1996), who was a health psychologist in the United Kingdom, introduced this term (Raissa \& Minton 2016). The purpose of using IPA is to produce an in- depth examination of a certain phenomenon about how participants are making sense of their particular personal and interactive social world experiences and not to generate any theory that can be generalized over the whole population. Actually IPA is considered as appropriate to respond to "openly framed research questions" (Smith and Eatough 2006).

IPA researches might have sample of 1 to 15 participants. A large sample size in IPA is generally very less, because a small sample size gives an opportunity to observe the similarities and differences between individuals. Therefore, IPA researchers may deliberate on more in depth of the study rather than increasing the breadth (Turpin et al., 1997, as cited in Igor \& Smith, 2014; Igor \& Smith 2014).

There are certain guiding principles, however, researchers can adapt the method to their own particular way of processing and doing interpretative the data (Smith \& et al. 1999).Following framework of IPA was used for analysis of data collected through open ended question items. This framework was suggested by Smith et al. (2009); Finlay, (2011), for analysis of qualitative data through IPA:

\begin{tabular}{|l|l|l|}
\hline Stage & Activity & Actions \\
\hline 1 & $\begin{array}{l}\text { Reading and re- reading } \\
\text { Text }\end{array}$ & $\begin{array}{l}\text { Significant responses from the readers statements, } \\
\text { sentences or quotes are identified/ underlined in the } \\
\text { transcripts (Open coding). }\end{array}$ \\
\hline 2 & Identifying themes & $\begin{array}{l}\text { Identification of and labeling of major and minor } \\
\text { themes. Working through the initial notes and writing } \\
\text { down in the right-hand margin themes that come }\end{array}$ \\
\hline
\end{tabular}




\begin{tabular}{|l|l|l|}
\hline 3 & Searching for connections & $\begin{array}{l}\text { forward, emphasizing both common and distinction } \\
\text { ideas }\end{array}$ \\
\hline 4 & $\begin{array}{l}\text { Clusters of themes are labelled in such a way that } \\
\text { display their spirit. Clusters of themes are produced by } \\
\text { grouping together meaningful themes, by developing } \\
\text { higher-order themes }\end{array}$ \\
\hline Production of summary & $\begin{array}{l}\text { Quotations are selected that illustrate theme and are } \\
\text { ordered coherently to illustrate the relationships between } \\
\text { the themes. }\end{array}$ \\
\hline 5 & $\begin{array}{l}\text { The narrative is based on the summary table: quotes } \\
\text { from participants are included to add depth and richness. } \\
\text { A single respondent's text may be written up as a case- } \\
\text { narrative }\end{array}$ & $\begin{array}{l}\text { Master -list for each transcript can be generated to } \\
\text { merge it in the consolidated list of master themes for the } \\
\text { group of participants (Smith et al., 2009; Finlay, 2011). }\end{array}$ \\
\hline
\end{tabular}

At first stage, we studied thoroughly the texts of whole collected data and open coding was done and initial notes were prepared. The next stage was to search for themes out of the open coding/ initial notes and label these themes as major and minor. We analyzed only themes which were directly relevant to our research questions.

\section{Analysis of Data}

The demographic information of the respondents is provided in the table below:

Table No. 1 Demographic information of participants

\begin{tabular}{lcc}
\hline Demographics & $\mathrm{n}$ & percentage \\
\hline Gender & 15 & 38.46 \\
Male & 24 & 61.54 \\
Female & 18 & \\
Qualification & 21 & 46.15 \\
PhD & 39 & 53.85 \\
Master/ MPhil & & \\
Total & \\
\hline
\end{tabular}


At the first stage, the participants' texts of replies was read and re- read for the purpose of open coding in the perspective of research questions. From open coding matrix of themes and sub- themes were identified. The detail of themes and sub- themes is given in below table:

Table-2: Stage- 2 Activity: Identifying themes and sub-themes

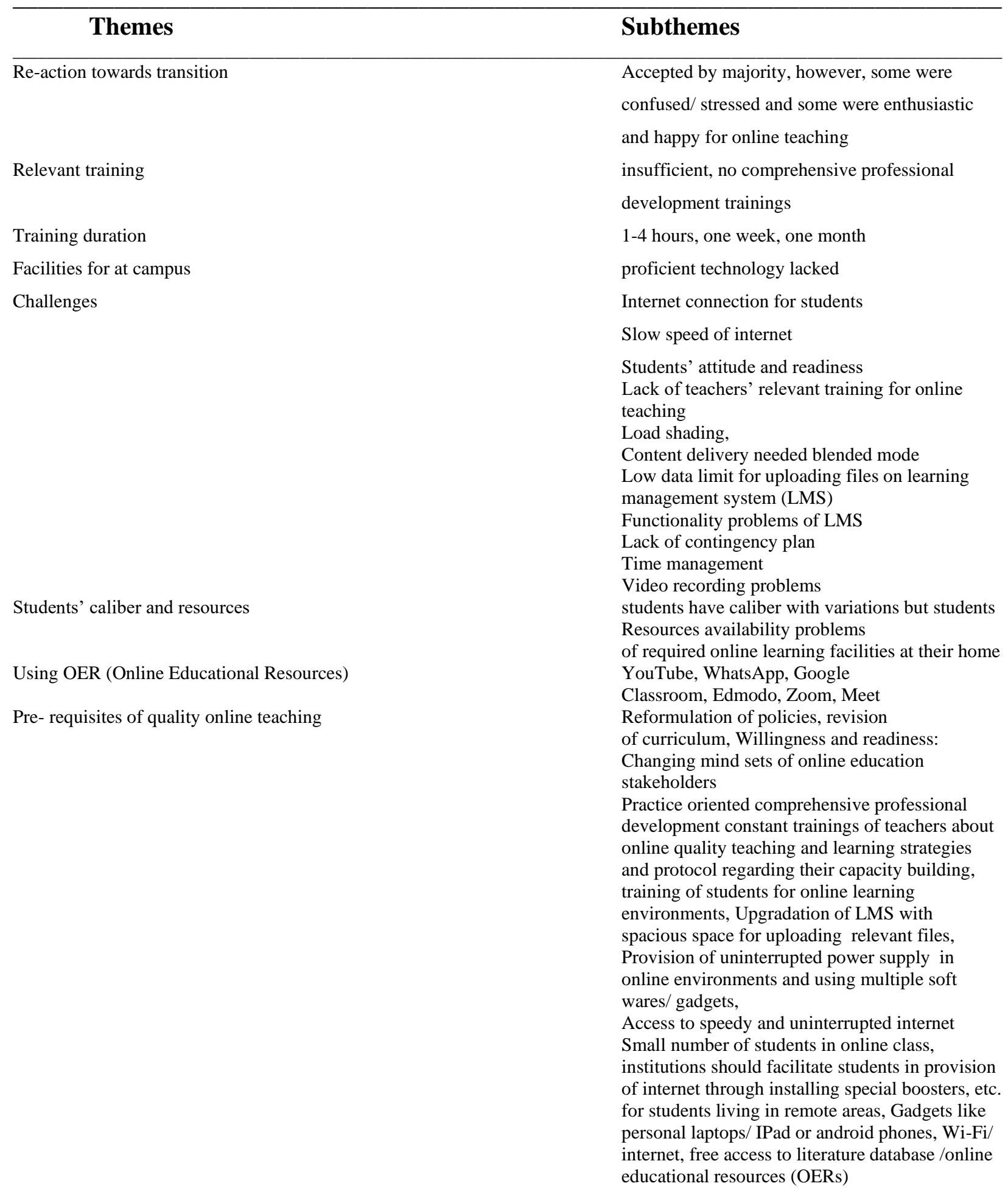


Effective gadgets for online education

Online effective techniques
Moodle, Zoom, Google, Bandwidth, Khan Academy, multimedia, meet classroom Educational television, smart class rooms Flipped and Blended learning

\section{Themes and sub themes identified:}

\section{(1) What was the university teachers' re-action towards transition from face-to-face} teaching to online teaching?

It is observed that generally, teachers re-act and fear about implementing any educational change and innovations (Anghelache \& Bentea, 2012).In current results, the theme 're-action towards transition' came as one of the most important themes as re-action towards any decision/ happening is the base for further actions/ re-actions. It was find out from analysis of texts of openended questions from majority of respondents were happy with their respective universities administration's decision of teaching transition from face to face to online teaching policies because they realized the importance of online teaching during pandemic era. However, some university teachers, who found themselves uncomfortable with online teaching, they were under stressed and confused. There were only two teachers (among 39) who were confused and were under stress. One said, "I was under stress", the other said, "I was confused what to do for online teaching". Another respondent said, "I was tense about this decision". However, overall teachers accepted the change with positive attitude towards online teaching. One teacher wrote, "I was excited that it was going to be enlightening opportunity for me to learn new things." A respondent described, "I was enthusiastic and happy for online teaching, it was the best opportunity to be at home and teach". Here the results are consistent with Doug, (2019) who observes that teachers generally, like the characteristic of online education as being not bound by time or space. The teachers' positive re-action towards change was observed in the current research, as compared to the previous researches, may be due to special crisis of COVID- 19 pandemic. The theme 'Using OERs (Online Educational Resources)' for self- professional development of teachers is one of the other important factor. It was found out that teachers usually utilize YouTube, WhatsApp, Google classroom, Edmodo, Zoom, and Meet, as their self-learning by using OERs.

\section{Stage- 3: Cluster of themes}

From above analysis it is obvious that online teaching and learning environment is rather innovative practice in higher education in the context of Pakistan. Although some universities like Virtual University has purely online education system and Allama Iqbal Open University and some other universities in Pakistan are offering some of their programs through online education mode. However, on the whole maximum Pakistani universities are offering traditional face to face mode of education, therefore in such universities, online teaching was a big challenge for teachers. The cluster of themes emerged from participants' views expressed in text are presented in the discussion below under the research questions:

\section{(2) What are the challenges that university teachers face during transition from face-to- face classroom teaching to online teaching?}

The theme: challenges identified: Participants shared challenges and problems that they faced during online teaching. The major among themes were slow speed of internet at campus, unsatisfactory functionality of learning management system (LMS), which was sometimes not working well. It disconnected frequently, which created embracement for teachers as well for 
students and effected the smooth functioning of online teaching- learning environment. One participant said, "It took too much time in uploading files / videos that were essential for students to share, however sometimes these were not uploaded". One participant called LMS "A tired LMS, an insufficient server". limitation in uploading relevant files for students, students' attitude and readiness, lack of relevant teaching gadgets like computer/ laptops, etc., lack of teachers' relevant professional training for online teaching, frequent load shading, nature of the content which often required blended learning mode, lack of coordination and contingency plan on the part of administration. From responses of the participants, it was discovered that majority of university teachers realized that lack of relevant professional development trainings for teaching online courses was the biggest challenge for university teachers. Therefore, consequently, there was a psychological pressure and stress among teachers for online teaching. Even the training that was provided to them, generally its duration was one hour to one week and during this training no practice-oriented sessions were given to teachers for demonstration, it was only theoretical. Frequent load shading was there, although at universities there were back up arrangements for power supply, however, many students did not have such facility at their homes which effected badly the delivery of instruction. The content that teachers were using was basically designed for face- to face delivery, therefore, in delivery of certain content online created immense difficulties for teachers. Sometimes teachers faced problems in recoding of lectures.

One teacher said, "Some of the portions of curriculum were incompatible for online teaching as it required demonstrations, laboratory practical experiments or field trips". A large number $(75 \%)$ of participants respond that they arranged online teaching resources like computer/ laptop, and internet by their own, however, to overcome load shading problem was very difficult. Another challenge was that maximum students did not have any experience of learning through online environments and resources. Such things may be called as pre- requisites of online teaching and learning.

\section{(3) What are university teachers' views about caliber and resources of students for learning through online?}

It was observed that the participants did realize that teaching- learning is two way process. Therefore, students' caliber and resources to learn through online education system are the most important components. The theme 'students' caliber and resources': Respondent answered that majority of the students had caliber for online with variation as they are generation of $21^{\text {st }}$ century, however, students living in remote areas could not benefit from online education programs due to the lack of resources like electricity and internet facility at their home/ in their area. The institutions to some extent send the material at home through courier which again arrived late at their home due to COVID- 19 restricted movement of courier services. In addition, teachers experienced that during online instruction students were found to be not ready for online learning, their attitude was casual and they were not serious towards learning through online instructions.

The cluster of themes that emerged from the open- ended questions about challenges of online teaching from participants are present in the figure-1 below: 
Figure- 1 Challenges of Online Teaching

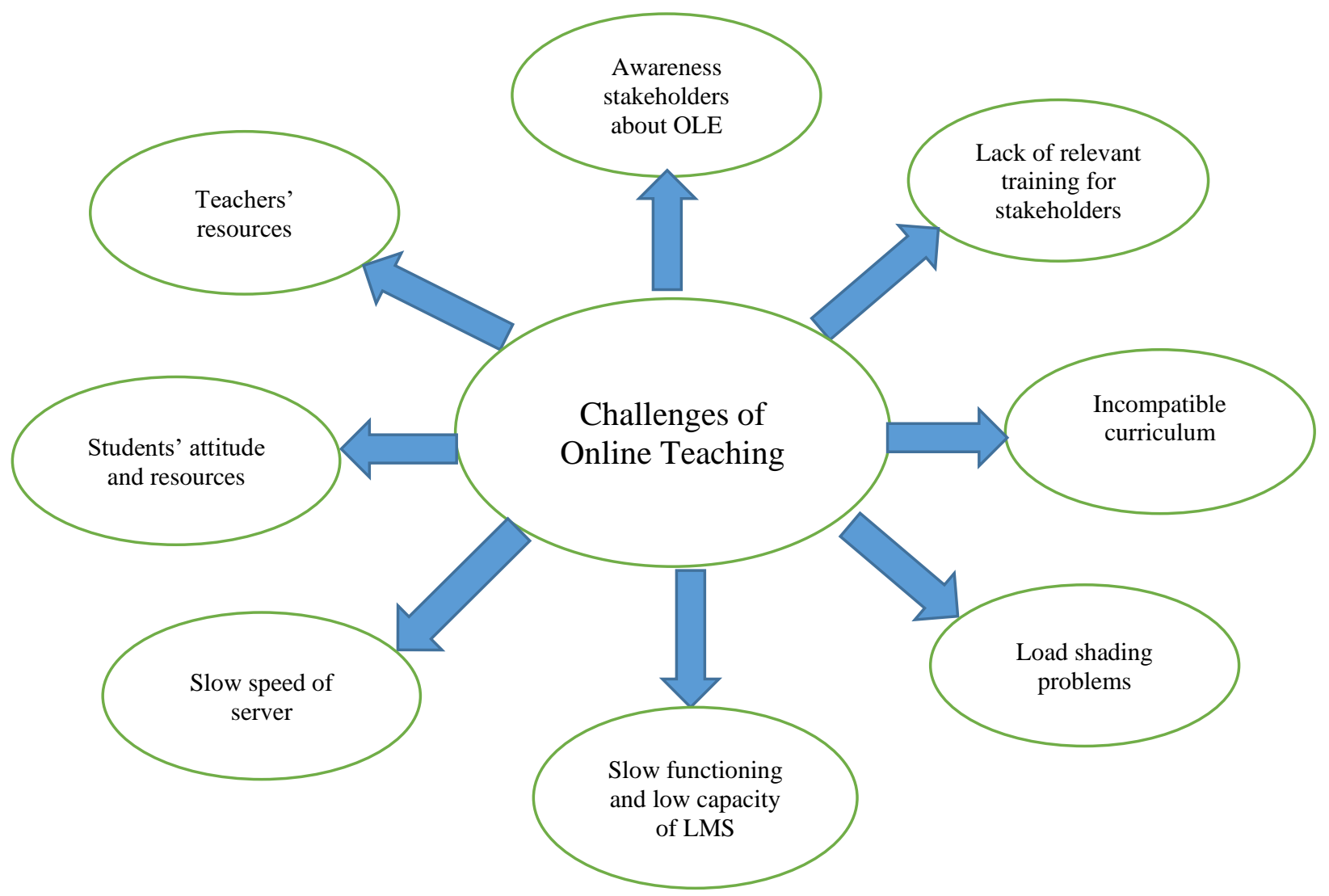

(4) What are university teachers' experiences regarding institutional support and infrastructure during transition period?

Participants' experiences were analyzed regarding institutional support and infrastructure during urgency transition period of face-to face to online teaching. The major findings emerged from responses of the participants were that majority of the participants were not satisfied with the institutional support for relevant online teaching training and infrastructure, especially with slow server speed, low function of learning management system (LMS), low capacity of LMS for uploading files, problems in lectures recording facilities and lack of contingency plan.

\section{(5) What are university teachers' perception about pre- requisites of quality based online education programs?}

The theme 'relevant training': There was found a consensus among participants that for provision of quality education (OLE) programs, there are certain pre- requisites of OLE that needs to be fulfilled before we launch OLE programs. Among these pre- requisites, practice oriented professional development of teachers for online teaching and assessment techniques is the most important elements as without relevant required training there can be no quality teaching. University teachers perceive that pre- requisites for successful implementation of any program or innovation delivery is the practice oriented training of all involved stakeholders about the 
innovative aspects of the program. The participants of the study were not at all satisfied with the brief training about online teaching. One respondent wrote it was 'insufficient' and 'theoretical'. Eight among 39 participants replied that they received 'no training' for online teaching. It was inferred from the responses that the duration of the training lasted from 1-4 hours and one respondent informed the duration was one week, another informed it was one month. The prerequisites of quality online education as emerged from participants' data are described below:

- Willingness and changing mind sets of online education stakeholders through creating awareness among masses about online education programs

- Reformulation of policies, revision of curriculum to make it compatible for online education platforms

- Practice-oriented training for students about how to learn using online learning plat forms (LMS, etc.) and about the protocol for online learning environments and assessment. In addition, institutions can facilitate students living in remote areas through installing special boosters, etc. Clusters centers can be established for group of students living in remote areas and such cluster center can be provided all relevant facilities of online education, like computer labs, uninterrupted power supply (UPS) and high speed internet

- Gadgets like personal laptops/ Ipads or android phones, uninterrupted power supply, WiFi/ internet for all teaching - learning stakeholders can be provided on certain terms and conditions without any demographic discrimination.

- Participants opined Moodle, Zoom, Google, Bandwidth, Khan Academy, multimedia, MEET classrooms, educational television can be described as the effective gadgets for online education whereas flipped instruction and blended learning can be said as the effective online teaching techniques for quality online educational programs, creation of smart class rooms, free access to literature database /online educational resources (OER) for online education for teachers and students at their living places also pre- requisite for successful online education.

- Free access for stake holders to multiple soft wares/ OERs and especially up-gradation of LMS with spacious space for uploading relevant files

- It was further emerged from text data of participants that using online communities' trend was found among university teachers. They were aware of the importance of online education and they were using online educational communities to enhance their competence like YouTube, WhatsApp, Google classroom, Edmodo, Zoom, Meet as online resources during their online teaching practices. One teacher said, "Flipped learning is the best technique for teaching online or technology integrated courses". Another teacher opined, "I find blended learning as the best technique for online education programs as it has some space to directly face to face interact with students along with online interaction. In this way we can fulfill the needs of such content which requires face to face interaction with students for effective learning". However, participants realized that paradigms of learning modes are changing in current scenarios and we need to change the mind sets of students and teachers through creating awareness about online education. One participant said, "We need to make our students aware and to realize the change of learning modes and teachers can do this through counselling of students".

- The theme 'pre- requisites of quality online education program' emerged from participants answer to the questions what can be done to improve online education programs.

\section{Stage- 4: Production of summary table of the themes: Summary of Themes}


- The major sub themes emerged are described in following figure- 2 :

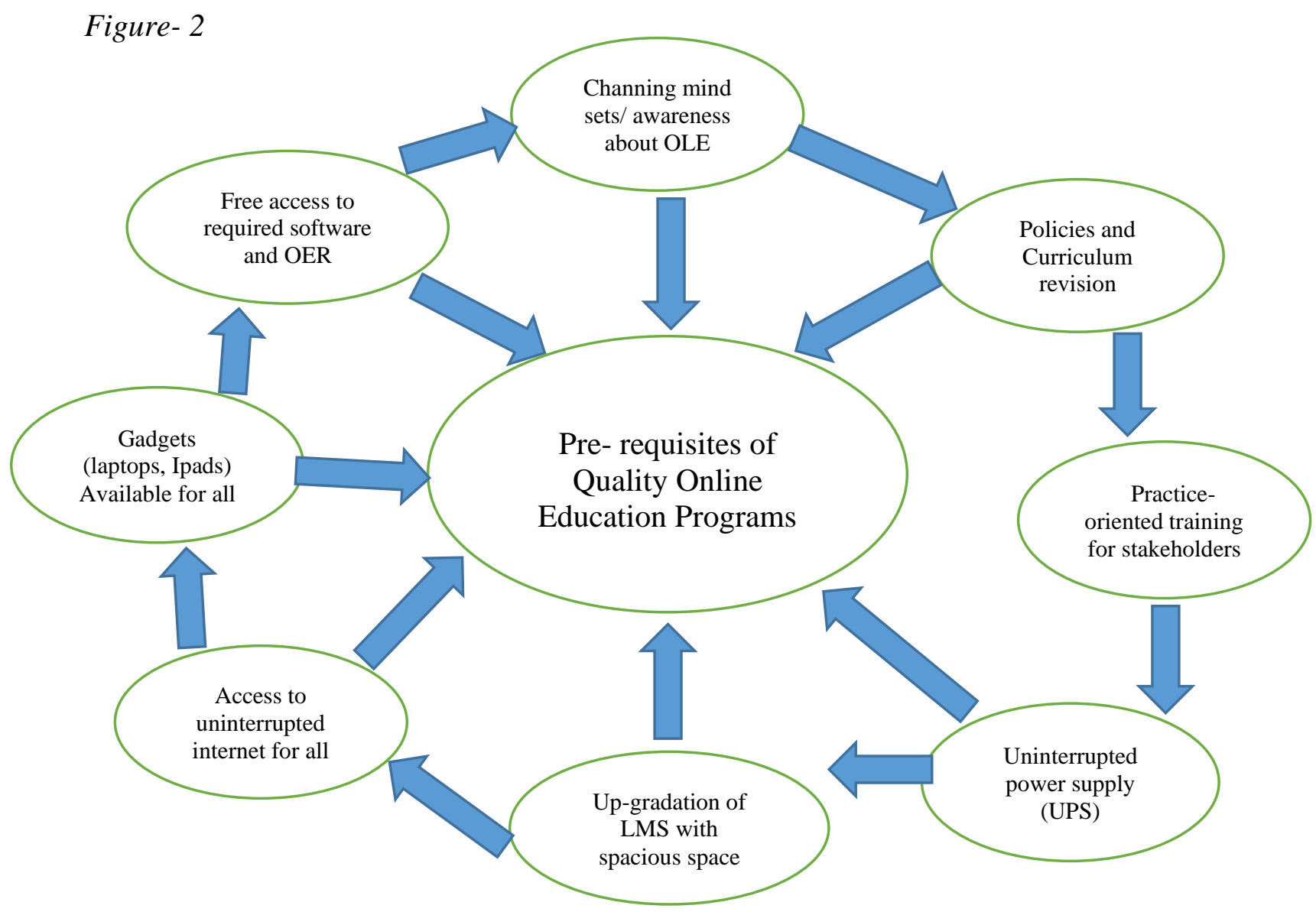

"While teachers' participation in online learning continues to edge up over all, it is extremely uneven -- by institution type, discipline and mind-set”(Doug, 2019). Issues relating to technology proficiency, time management and workload were observed as barriers to teaching online. Studies further identified that teachers proficiently adjusted to the online environment as they gained more professional experience (Wingo\& Moss, 2017).

\section{Stage- 5: Construction of a cohesive narrative}

After analysis of participants' personal experiences and views that were expressed in certain open- ended questions, it was evident that majority of university teachers accepted the transition of face- to face to online teaching. However, teachers did realize that comprehensive relevant training regarding how to teach online was not provided. Teachers faced multiple problems during urgency period of online teaching like insufficient and unsatisfactory institutions infrastructure required for online teaching and incompatible curriculum content for online teaching, non-serious attitude of students and lack of resources for students living in remote areas. Therefore, participants reflected that before launching OLE (online education) programs, the institutions may make assure about completing certain pre- requisites of OLE like formulating online education polices, curricula, up-grading their server, LMS, and equipping online education stakeholders with relevant trainings and equipment. 


\section{Discussion on Results, Conclusion and Actions Recommended}

Our research confirmed some common problems and challenges of online teaching at university level and provided a collection of predictions about the future challenges of online teaching during COVID-19 in the context of Pakistan. Findings are found consistent with researches of Kebritchi, Lipschuetz, \& Santiague, 2017; Doug, 2019; Liguori\& Winkler, 2020; UNESCO, 2020; Mazumder\& et.al, 2021. The data for our present research was collected during August- September 2020 through open ended questionnaire from volunteer teachers. The major findings that emerged after scientific analysis of data were that mostly university teachers accepted this prompt transition of teaching paradigm, however, they were under stressed because they did not have any relevant practical training to teach online. Teachers were not satisfied with the training provided by universities and the quality of infrastructure required for online teaching. Teachers perceived that mostly students did have caliber likewise many students, who were living in remote areas, did not have the access to internet and electricity which are the pre- requisites for online teaching- learning. There was a common consensus among university teachers that before launching online educational programs all pre- requisites of online education may be fulfilled at satisfactory level. It is therefore, recommended that before launching online education courses\} programs, we may analyze the grassroots realities of each and every area of the country through need assessment. The current study has implications in understanding the difficulties and challenges of teachers and students and the material and physical resources that are required for online teaching and learning.

\section{References}

Allen, I. and Seaman, J. (2014) Grade Change: Tracking Online Learning in the United States Wellesley MA: Babson College/Sloan Foundation. Retrieved from http://www.Joshuabates.ca/2014/01/19/tracking-online-learning-in-the-usa-ando ntario/\#sthash.nCMMnbnS.dpuf

Allen, E. \& Jeff Seaman (2011). Going the Distance Online Education in the United States, 2011. Published by Babson Survey Research Group and Quahog Research Group, LLC All rights reserved.

Anghelache, Valerica\&Bentea, Cristina. (2012). Educational changes and teachers' attitude towards change. Procedia - Social and Behavioral Sciences. 33. 593-597. 10.1016/j.sbspro.2012.01.190.

Basilaia, G. ,Dgebuadze, M., Kantaria, M., \&Chokhonelidze, G. (2020). Replacing the classic learning form at universities as an immediate response to the COVID-19 virus infection in Georgia. International Journal for Research in Applied Science \& Engineering Technology, 8 (III).

Butcher, Neil \&Hoosen, Sarah (2014). Exploring the Business Case for Open Educational Resources. Published by: Commonwealth of Learning1055 West Hastings, Suite 1200Vancouver, British ColumbiaCanada V6E 2E9

Bonk, C. J. (2001). Online Teaching in an Online World (Bloomington, Ind.: Course Share, 2001).

Carey, K. (2020). Is everybody ready for the big migration to online college? Actually, no. The New York Times. https://www.nytimes.com 
Igor Pietkiewicz\& Jonathan A. Smith (2MishM014). A practical guide to using Interpretative Phenomenological Analysis in qualitative research psychology. CzasopismoPsychologiczne - Psychological Journal, 20, 1, 2014, 7-14.

Dima Gabriela \&Bucu, tăMihaela Dana (2016). Z Psychodrama Soziometr (2016) (Suppl) 15:6981 DOI 10.1007/s11620-015-0296-7 @ Springer Fachmedien Wiesbaden 2016

Doug Lederman (2019). October 30, 2019 Professors' Slow, Steady Acceptance of Online Learning: A Survey. Retrieved on $20^{\text {th }}$ October 2020 from: https://www.insidehighered.com/news/survey/professors-slow-steady-acceptance-onlinelearning-survey

Finlay, L. (2011). Phenomenology for therapists: Researching the lived world. Chichester, England: Wiley-Blackwell

González-Sanmamed, M., Muñoz-Carril, P. C., \&Sangra, A. (2014). Level of proficiency and professional development needs in peripheral online teaching roles. The International Review of Research in Open and Distributed Learning, 15(6), 162-187. https://doi.org/10.19173/irrodl.v15i6.1771

Kebritchi, M., Lipschuetz, A., \&Santiague, L. (2017). Issues and Challenges for Teaching Successful Online Courses in Higher Education: A Literature Review. Journal of Educational Technology Systems, $46 \quad$ (1), $44^{-} \quad 29$. https://doi.org/10.1177/0047239516661713

Lichoro, D. Muturia (2015). "Faculty preparedness for transition to teaching online courses

in the Iowa Community College Online Consortium" (2015). Graduate Theses and Dissertations. 14376. https://lib.dr.iastate.edu/etd/14376

Liguori E. \& Winkler C. (2020). From Offline to Online: Challenges and Opportunities for Entrepreneurship Education Following the COVID-19 Pandemic. Entrepreneurship Education and Pedagogy2020, Vol. 3(4) 346-351. DOI: 10.1177/2515127420916738journals.sagepub.com/home/eex

Limberg, L. (2008). Phenomenography. In L. Given (Ed.), The SAGE encyclopedia of qualitative research methods. (pp. 612-615). Thousand Oaks, CA: Sage. p. 611- 614

Marton, F., \& Pong, W. Y. (2005). On the unit of description in phenomenography. Higher Education Research \& Development, 24(4), 335-348. Retrieved from http://dx.doi.org/10.1080/07294360500284706

Mazumder A, BandhuKalanidhi K, Sarkar S, Ranjan P, Sahu A, Kaur T, KaurD, Bhattacharya A, PriyadarshiniSuna S, Prakash B, Deb KS, Wig N (2021). Psycho-social and behavioural impact of COVID 19 on young adults: Qualitative research comprising focused group discussion andin-depth interviews, Diabetes \& Metabolic Syndrome: Clinical Research \& Reviews (2021), doi: https://doi.org/10.1016/j.dsx.2020.12.039

Raissa M. Miller\&Casey A. Barrio Minton (2016). Experiences Learning Interpersonal Neurobiology: An Interpretative Phenomenological Analysis Journal of Mental Health Counseling (2016) 38 (1): 47-61. 
Sammons. M. (2003). "Exploring the New Conception of Teaching and Learning in Distance Education," in Handbook of Distance Education, M. G. Moore and W. G. Anderson, eds. (Mahwah, N.J.: Lawrence Erlbaum Associates, 2003), pp. 387-400.

Saxena, K. (2020). Coronavirus accelerates pace of digital education in India. EDII Institutional Repository

Schweisfurth M. (2020). Learner-centred pedagogy: Towards a post-2015 agenda for teaching and learning. International Journal of Educational Development. Volume 40, January 2015, Pages 259-266. DOI: $10.1016 /$ j.ijedudev.2014.10.011

Singh, V., Thurman, A. (2019). How many ways can we define online learning? A systematic literature review of definitions of online learning (1988-2018). American Journal of Distance Education, 33(4), 289-306

Smith, J. A., Flowers, P., \& Larkin, M. (2009). Interpretative phenomenological analysis: RaiTheory, method and research. Los Angeles, CA: SAGE

Smith, J. A., \&Eatough, V. (2006). Interpretative phenomenological analysis. In G. M. Breakwell, S. Hammond, C. Fife-Schaw, \& J. A. Smith (Eds.), Research methods in psychology (3rd edn.). London: Sage Publications.

UNESCO, (2020). Global Education Monitoring (GEM) Report, 2020: Inclusion and education: all means all, 2020, available at https://unesdoc.unesco.org/ark:/48223/pf0000373718.

Wingo,N. P., Ivankova, N. V., \& Moss, J. A. (2017) Faculty perceptions about teaching online: exploring the literature using the technology acceptance model as an organizing framework, Online Learning 21(1), 15-35. doi: 10.10.24059/olj.v21i1.761 